\title{
PREVALENCIA DE ALGUNAS ENFERMEDADES INFECCIOSAS EN BOVINOS DE RESGUARDOS INDÍGENAS DEL CAUCA, COLOMBIA, 2017
}

\section{PREVALENCE OF SOME INFECTIOUS DISEASES IN CATTLE OF THE INDIGENOUS RESGUARDS IN CAUCA, COLOMBIA 2017}

\begin{abstract}
Diana C. Rivera ${ }^{1}$, Juan C. Rincón ${ }^{2 *}$, Juan C. Echeverry ${ }^{3}$
${ }^{1}$ Médico Veterinaria Zootecnista, Grupo Producción Pecuaria Sostenible. Carrera 27 \#10-02, Pereira-Risaralda, Colombia, e-mail: dianacra_94@utp.edu.co, (iD https://orcid.org/0000-0003-1496-7207; 'Zootecnista, Ph.D. en Ciencias Agrarias, Docente investigador del programa de Medicina Veterinaria y Zootecnia. Universidad Tecnológica de Pereira, Grupo de investigación Producción Pecuaria Sostenible. Pereira-Risaralda, Colombia, e-mail: rincon.juan@utp.edu.co, (iDhttps://orcid. org/0000-0002-6769-6407; ${ }^{3}$ Médico Veterinario Zootecnista, Especialista en reproducción, Docente del programa de Medicina Veterinaria y Zootecnia. Universidad Tecnológica de Pereira, Pereira-Risaralda, Colombia, e-mail: veteriloco@utp.edu. co, (iDhttps://orcid.org/0000-0002-1267-9204. *autor de correspondencia: rincon.juan@utp.edu.co.
\end{abstract}

Rev. U.D.C.A Act. \& Div. Cient. 21(1):507-517, Julio-Diciembre 2018 https://doi.org/10.31910/rudca.v21.n2.2018.983

Artículo de acceso abierto publicado por Revista U.D.C.A Actualidad \& Divulgación Científica bajo una licencia Creative Commons CC BY-NC 4.0

\section{RESUMEN}

La zona del Cauca posee resguardos indígenas que han presentado diferentes problemáticas asociadas a la lucha armada en Colombia, lo que ha limitado que las entidades puedan realizar programas de control de enfermedades bovinas. Por lo anterior, el objetivo de este trabajo fue determinar la prevalencia de algunas enfermedades infecciosas, de carácter reproductivo, en el ganado bovino, de tres resguardos indígenas del Cauca, 2017. Se recolectaron muestras sanguíneas de 30 vacas, para determinar la prevalencia de Neospora caninum, Brucella abortus, diarrea viral bovina (DVB), rinotraqueitis infecciosa bovina (IBR) y Leptospira sp. serovares Hardjo prajitno, bovis y Pomona. Las pruebas, se realizaron por ELISA, rosa de bengala y microaglutinación. Mediante el software $\mathrm{R}$, se efectuó un análisis descriptivo y se determinaron las prevalencias para cada enfermedad, se estimaron las co-infecciones y se realizó un modelo de regresión logística, para determinar el efecto del hato, resguardo, componente racial, grupo etario, número de animales y tamaño del hato, sobre la positividad a las enfermedades. Se encontró una prevalencia del $36 \%$, para $N$. caninum; $60 \%$, DVB; 30\%, IBR; 0\%, B. abortus; Leptospira spp. serovares Harjo prajitno, $26 \%$; Hardjo bovis, $12 \%$ y Pomona, $10 \%$. De acuerdo con el análisis de riesgo, la seropositividad para DVB e IBR estuvo asociada con el resguardo donde habitaban los animales, en este caso, Tacueyó tuvo más riesgo y estuvo directamente relacionado con el área de los hatos; entre mayor área más animales fueron positivos. En general, se encontró que la situación de la zona es similar a la de otros lugares de Colombia.

Palabras clave: Neospora caninum, Brucella abortus, diarrea viral bovina, rinotraqueitis Bovina, leptospirosis bovina (Thesaurus: Mesh).

\section{ABSTRACT}

The Cauca region in Colombia has indigenous reservations that have presented different problems associated with the armed conflict, which has limited the entities to carry out bovine disease control programs. Therefore, the aim of this work was to determine the prevalence of some infectious diseases of reproductive traits in cattle of three indigenous resguards in Cauca, 2017. Blood samples of 30 cows were collected to determine the prevalence of Neospora caninum, Brucella abortus, bovine viral diarrhea (BVD), Infectious bovine rhinotracheitis (IBR) and Leptospira sp. serovars Hardjo 
prajitno, bovis and Pomona. The tests were performed by ELISA, rose bengal and microscopic agglutination. Using $\mathrm{R}$ software, a descriptive analysis was carried out and the frequencies for each disease were estimated. In addition, co-infections between diseases were estimated and a logistic regression model was performed to determine the effect of the herd, reservation, racial component, age group, number of animals and size of the farm on the disease positivity. The prevalence was $N$. caninum $36 \%$, BVD $60 \%$, IBR $30 \%$, B. abortus $0 \%$, Leptospira spp. serovars Hardjo prajitno $26 \%$, Hardjo bovis $12 \%$, y Pomona $10 \%$. According to the risk analysis, the seropositivity for BVD and IBR were associated with the place where the animals lived, in this case Tacueyó, but this was directly related to the size of the herds, since the greater, the area more animals were positive. In general, it was found that the situation in the region is similar to that of other sites in Colombia.

Keywords: Neospora caninum, Brucella abortus, bovine viral diarrhea, bovine rhinotracheitis, bovine leptospirosis (Thesaurus: Mesh).

\section{INTRODUCCIÓN}

Las alteraciones reproductivas son uno de los principales problemas que presentan las ganaderías colombianas y son el resultado de enfermedades de carácter infeccioso y no infeccioso, asociados con factores de manejo, medidas sanitarias, genética animal y nutrición. Múltiples enfermedades pueden afectar la reproducción en el ganado bovino, como la leptospirosis, la Brucelosis, la Neosporosis, la diarrea viral bovina y la rinotraqueitis infecciosa bovina, que no solo afectan la salud y la producción de los animales, sino que pueden poner en riesgo la salud pública (Fedegan, 2011).

Los resguardos indígenas del Cauca (Colombia), se encuentran en una zona de alta diversidad biológica y étnica, con poca presencia del Estado y estratégica para los grupos armados ilegales, lo que ha generado problemas de orden público durante décadas (ACNUR-ONU, 2008). Todo esto, ha limitado a las entidades para realizar programas informativos, que permitan a la población tener condiciones adecuadas en sus hatos y sistemas de producción. Adicionalmente, no existen reportes relacionados con el estado de salud de los animales, desconociendo la prevalencia e incidencia de patógenos, lo que constituye un riesgo para la ganadería del país, debido a la posibilidad de intercambio y de movimiento de ganado. La falta de información epidemiológica impide desarrollar programas de control, que garanticen la salud de los animales y la productividad (Camacho et al. 2015).

Entre las enfermedades que afectan la reproducción, se encuentran parásitos, como el protozoario Neospora caninum, que se conoce mundialmente por ser uno se los causantes principales de abortos en el ganado, es de difusión mundial $y$, hasta el momento, no se ha tenido reportes de infección al ser humano (Bedoya et al. 2018).

Entre las enfermedades virales, se encuentra la diarrea viral bovina (DVB), que genera pérdidas económicas en las producciones bovinas (Moreno et al. 2017), ya que se estima que, aproximadamente, el $60 \%$ del ganado en zonas endémicas se infecta con el virus durante su vida. La DVB es capaz de permanecer latente en su hospedero, debido a que puede infectar fetos y causar tolerancia inmune (Ostachuk, 2016).

Otro agente etiológico de tipo viral es el herpes virus bovino tipo 1, que produce la rinotraqueitis infecciosa bovina (IBR). Es una enfermedad que genera alteraciones respiratorias y reproductivas en el ganado y puede permanecer latente por largos períodos de tiempo y activarse por inmunosupresión, haciendo que el control sea más complejo y la diseminación del virus pueda llegar a ser imperceptible en el hato (Parreño et al. 2010). La infección es endémica en Colombia y la vacunación no es obligatoria, lo que genera pérdidas económicas en la industria ganadera (ICA, 2017).

Finalmente, la Leptospira spp. y Brucella abortus son agentes de carácter bacteriano, que afectan la salud animal y generan pérdidas económicas importantes (ICA, 2017), a tal punto que en la región de Sumapaz (Colombia), se reportó que la brucelosis causó pérdidas económicas entre los 588 y 772USD, en producción lechera por animal y se estimó que los costos podrían llegar a los 2412USD anuales por animal (Arenas \& Moreno, 2016). Además, es importante resaltar que, al existir un manejo inadecuado de estas enfermedades, la morbilidad, la mortalidad y la diseminación, se incrementan notablemente. Leptospira spp. y B. abortus son agentes de carácter zoonótico, convirtiéndolos en un riesgo para la salud pública, sobre todo, para aquellas personas que tienen contacto directo con los animales o consumen su derivados (Arenas et al. 2017). Por lo anterior, el objetivo de esta investigación fue determinar la prevalencia de algunas enfermedades infecciosas de carácter reproductivo en el ganado bovino, en los resguardos indígenas San Francisco, Toribío y Tacueyó, en el departamento del Cauca, en 2017.

\section{MATERIALES Y MÉTODOS}

Consideraciones éticas. Este trabajo presenta riesgo mínimo y tiene el aval del comité de ética de la Fundación Universitaria Autónoma de las Américas (Acta 22). Además, contó con el apoyo de la asociación de cabildos de Toribio, Tacueyó y San Francisco, el proyecto Nasa y la administración Municipal de Toribio (convenio interadministrativo 107 de 2006). 
Localización. La investigación, se realizó en el municipio de Toribío (2॰57'2"N y 76¹6'17'O), en los resguardos indígenas de San Francisco, Tacueyó y Toribío, ubicados en el nororiente del departamento del Cauca, Colombia. Presenta una altura sobre el nivel del mar de $1.700 \mathrm{~m}$ en promedio, temperatura promedio de $19^{\circ} \mathrm{C}$ y precipitación media anual de $1.959 \mathrm{~mm}$.

Caracterización de los animales y las producciones. Según el inventario ganadero de Colombia, en el 2015, en esta zona, había 4.090 bovinos, en 307 producciones ganaderas, de las cuales, fue posible muestrear 5 hatos por resguardo (15 en total, aproximadamente, el 5\%), de los que se tomaron, al azar, 2 animales, para realizar un estudio de tipo transversal $(n=30)$; es importante notar, que para una población de 4.090 bovinos, con una heterogeneidad del $50 \%$ y un nivel de confianza del 95\%, el margen error calculado para 30 muestras, es del $18 \%$.

De cada uno de los animales, se le tomó la información necesaria para clasificarlos por grupo etario: jóvenes, hasta 4 partos; adultos, más de 4 partos y tipo racial (Puros, Cruzados). Adicionalmente, mediante una encuesta, se tomó información relacionada con los planes sanitarios, la presentación de buenas prácticas ganaderas, de protocolos de vacunación, tipos de pasto, resguardo al que pertenecen, tamaño de cada hato en número de animales y área. Con respecto al número de animales, los hatos fueron clasificados, como pequeños, cuando tenían menos de 10 animales; medianos, de 10 a 50 y grandes, más de 50 animales. Con respecto al área, los hatos fueron catalogados, como pequeños, cuando tenían menos de 10 hectáreas; medianos, de 10 a 30 hectáreas y grandes, de más de 30 hectáreas. Esta clasificación fue usada en el modelo de regresión logística.

Toma de muestras. A cada uno de los animales, se le tomó una muestra de sangre por punción de la vena yugular o coccígea, usando agujas número 18 y tubos BD Vacutainer ${ }^{\circledR}$ de $3,0 \mathrm{~mL}$, sin anticoagulante; luego, se transportaron en una nevera portátil $\left(4-8^{\circ} \mathrm{C}\right)$, lo más pronto posible, para evitar hemolisis.

Pruebas serológicas. Los sueros, se sometieron a pruebas de laboratorio, con los métodos de Rosa de Bengala, para determinar la prevalencia de Brucella sp., ELISA para evaluar anticuerpos totales contra Neospora sp, el virus de la diarrea viral bovina y el virus de la IBR. Finalmente, se usó la prueba de aglutinación microscópica, para determinar la presencia de anticuerpos contra Lesptospira sp. (MAT, prueba serológica estándar para leptospirosis, según OIE, OPS y OMS). Las muestras fueron enviadas vía terrestre al laboratorio ICA (Instituto Agropecuario Colombiano), en Pereira, Risaralda y al laboratorio médico veterinario LMV, en Bogotá, Cundinamarca.
Análisis estadístico. A partir de los datos recolectados, se realizó un análisis descriptivo inicial y se estimaron las frecuencias de cada una de las enfermedades, con sus respectivos intervalos de confianza del 95\%. También, se estimaron las co-infecciones entre enfermedades y se realizó un modelo de regresión logística, para determinar el efecto del resguardo, el componente racial, el grupo etario, el tamaño de la finca en número de animales y área, sobre la positividad, a cada una de las enfermedades. El modelo utilizado fue:

$$
\operatorname{Logit}\left(P_{\text {enf }}\right)=B_{0}+B_{1} X_{1}+B_{2} X_{2}+B_{3} X_{3}+B_{4} X_{4}+B_{5} X_{5}+e
$$

Dónde: $P_{\text {enf }}$ es la probabilidad de que un individuo sea positivo a la enfermedad; $B$ os el intercepto; $B_{1}$ es el efecto (coeficiente) del resguardo (Toribío, San Francisco y Tacueyó); $B_{2}$ es el efecto del componente racial (Puros, Cruzados); $B_{3}$ es el efecto del grupo etario (jóvenes o adultos); $B_{4}$ es el tamaño del hato en número de animales (pequeño, mediano y grande); $B_{5}$ es el tamaño del hato en área (pequeño, mediano y grande); e es el vector de efectos aleatorios del residual y $X_{i}$ corresponde a la matriz de incidencia que relaciona los registros con los efectos.

Finalmente, a partir de los factores de riesgo significativos, se calculó la razón de probabilidades (OR: odds ratio), de cada uno de ellos. Todos los análisis, se realizaron mediante el software R (R Core team, 2015).

\section{RESULTADOS Y DISCUSIÓN}

Caracterización de las producciones. Los resultados indican que el $53 \%$ eran animales adultos y el $47 \%$, ganado joven. Con respecto a los componentes raciales, la raza más frecuente fue la Normando (60\%), que procedía, principalmente, del departamento de Caldas. Las otras razas importantes fueron Holstein, Pardo Suizo y Jersey, cada una con 6,7\%. El grupo racial menos frecuente fue los cruces con cebú $(3,3 \%$ ) (Figura 1a). Lo más común fueron las praderas de pasto Kikuyo (Pennisetum clandestinum), que se encontraron en $60 \%$ de los predios. Con respecto al número de animales, el 50\% de los predios presentó menos de 10 animales (pequeños); el $23,3 \%$, de 10 a 30 animales (mediano) y el $26,7 \%$, más de 30 animales (grande). El comportamiento del área de los hatos se presenta en la figura 1b, donde se observa, también que, respecto al área, la mayoría de hatos son pequeños; sin embargo, la correlación entre el número de animales y el área del hato fue solo de 0,19 , lo que muestra la poca relación entre las dos variables, mostrando que no necesariamente los hatos de mayor área tienen más animales.

Resulta interesante observar que Normando fue la raza más frecuente en los hatos muestreados, seguido de razas destinadas para la lechería especializada, lo cual, concuerda con características climáticas asociadas a la altura reportadas en 

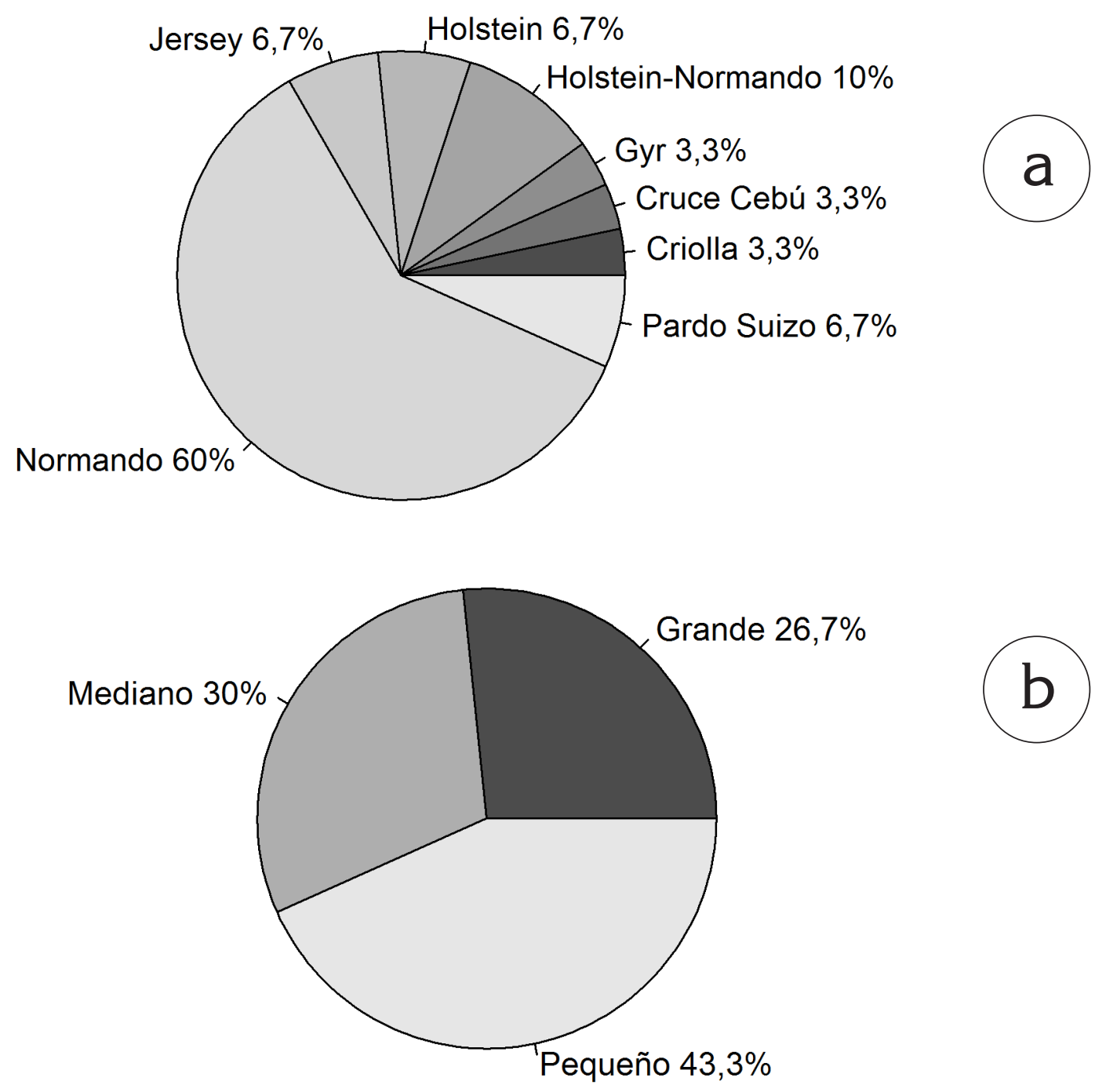

Figura 1. a. Caracterización de las razas y b. tamaño en área de los hatos muestreados en los resguardos indígenas San Francisco, Toribío y Tacueyó (CAUCA).

este trabajo, típicas de la lechería especializada en el trópico (Holmann et al. 2004), pero mostrando una preferencia importante por la ganadería doble propósito, evidenciada en el ganado Normando. Es importante notar que las praderas de kikuyo y las razas de ganado usadas en las producciones coinciden con lo reportado, comúnmente, en las ganaderías especializadas de Colombia (Holmann et al. 2004), lo que resulta llamativo, si se tiene en cuenta las dificultades para la llegada de las instituciones gubernamentales, a esta zona del país.

En la encuesta realizada a los propietarios de cada hato, se les preguntó si tenían protocolos de vacunación y si manejaban o conocían sobre las buenas practicas ganaderas
(BPG). Ninguno de los hatos se encontraba certificado en BPG y no había un programa de vigilancia durante las vacunaciones; sin embargo, sí reconocían algunas características de las BPG, pero no eran aplicadas en sus establecimientos. A partir de la información suministrada por los propietarios de los hatos, se encontró que el $93 \%$ de los animales fueron vacunados contra fiebre aftosa; el $53 \%$, contra brucelosis y el $16 \%$, con la vacuna triple para Carbón Sintomático, Edema Maligno y Pasteurelosis Bovina. No se reportó vacunación para otras enfermedades.

En cuanto a las buenas prácticas ganaderas, ninguno de los productores manifestó realizarlas, lo cual, es importante, si se tiene en cuenta que las enfermedades evaluadas en este 
trabajo, se pueden prevenir y controlar, si se toman medidas que garanticen un ambiente con las condiciones que eviten la entrada de agentes infecciosos (Argaiz, 2016). Por otro lado, es conveniente notar que existen muy pocos reportes sanitarios sobre las enfermedades presentes en el ganado criado por las poblaciones indígenas, lo que es preocupante, si se considera que esta puede ser una población de alto riesgo. Por lo anterior, es recomendable realizar programas de apoyo y de capacitación a la población indígena de la zona, para fortalecer sus sistemas de producción.

En Colombia y, en especial, en los resguardos indígenas de esta área del Cauca, los medios que les permita realizar actividades protocolarias para cuidar de sus hatos son muy bajos, por lo que se desconoce cuál es el verdadero estado sanitario de los animales. En general, no hay un manejo adecuado en cada granja, no se da mucha importancia a las labores de control y de prevención para los animales en producción y, más aún, cuando muchos de ellos son traídos de otros departamentos del país, que ingresan sin conocer su estado de salud y que se pueden convertir en un foco de infección para el resto de los animales (Argaiz, 2016). Todo ello, hace que esta región pueda ser considerada como una población en riesgo.

Por otra parte, en la tabla 1, se presenta la descripción general de los hatos muestreados en cada uno de los resguardos indígenas, con el área promedio y el número de animales. Los hatos de esta zona Caucana presentaron una altura sobre el nivel del mar promedio de $2.335,8$ metros, un poco más alta a la reportada, como promedio de la población. En general, la mayoría de hatos fueron pequeños con respecto al número de animales, aunque algunos presentaban grandes extensiones de tierra, no acordes con la cantidad de animales. La carga promedio fue de 2,11 20,63 animales/ha, con una carga mínima de 0,07 animales/ha y una máxima de 6 animales/ha. Respecto a la carga promedio encontrada, el tamaño promedio de los hatos y la extensión, es similar a lo reportado en otras zonas de Colombia (Fedegán, 2015); sin embargo, los valores mínimos de carga de 0,07 animales/ ha pueden evidenciar problemas importantes de la eficiencia productiva de la zona.

Respecto a la edad promedio de los animales fue de 5,2 años, con una media de 2,6 partos; sin embargo, Toribío presentó valores medios más bajos, evidenciando hatos más jóvenes que en San Francisco y en Tacueyó. En general, Toribio mostró la mayor densidad de animales por hectárea y Tacueyó, la menor. Los demás datos, se presentan en la tabla 1.

Según el inventario ganadero de Colombia, en el 2015, el municipio de Toribio experimentó un incremento en el inventario ganadero y en el número de predios con bovinos (Fedegán, 2015). Para ese año, se reportaron 307 predios, con 4.090 bovinos (entre producción de leche y ceba), de los cuales, 2.621 fueron hembras y 1.469 machos. Es importante notar que el número de hatos lecheros debe ser mucho menor al reportado en las estadísticas generales para el municipio, porque las producciones bovinas de la zona

Tabla 1. Características de los hatos lecheros, muestreados en los resguardos indígenas San Francisco, Toribío y Tacueyó (CAUCA).

\begin{tabular}{|l|c|c|c|c|c|}
\hline \multicolumn{1}{|c|}{ Variable } & Estadístico & Toribío & San Francisco & Tacueyó & General \\
\hline \multirow{2}{*}{ m.s.n.m (m) } & & 2328,4 & 2360,0 & 2319,0 & 2335,8 \\
\cline { 2 - 6 } & S.D & 308,7 & 386,4 & 9,1 & 234,7 \\
\hline \multirow{2}{*}{ Área (Hectáreas) } & & 4,6 & 19,3 & 99,0 & 40,9 \\
\cline { 2 - 6 } & S.D & 3,7 & 9,2 & 82,8 & 31,9 \\
\hline \multirow{2}{*}{ Edad (Años) } & & 3,9 & 5,7 & 6,1 & 5,2 \\
\hline \multirow{2}{*}{ Número de partos } & S.D & 2,3 & 2,1 & 2,0 & 2,1 \\
\hline \multirow{2}{*}{ Número de animales } & & 1,4 & 3,1 & 3,4 & 2,6 \\
\cline { 2 - 6 } & S.D & 1,1 & 1,8 & 1,3 & 1,4 \\
\cline { 2 - 6 } & & 9,3 & 34,5 & 54,6 & 32,8 \\
\hline
\end{tabular}

m s.n.m $(\mathbf{m})=$ metros sobre el nivel del mar en metros

S.D = Desviación estándar, = Media 
presentan mayor vocación por la ganadería doble propósito y de ceba (Fedegán, 2015). Aunque el número de animales por hato de este trabajo es mayor al tamaño medio de los hatos de la zona, reportado por Fedegán (2015), en general, coinciden en que en la región los hatos son pequeños respecto al número de animales, situación similar a la del resto del país (Holmann et al. 2004). En este trabajo, se tuvo una muestra de 30 animales que, aunque pequeña, es una primera aproximación a la situación de esta zona de Colom- bia que, históricamente, ha sido golpeada por el conflicto armado y el abandono gubernamental y, por este motivo, se sospechaba que fuera un sitio de alto riesgo, para la diseminación de enfermedades al resto del país.

Prevalencias y co-infecciones. Referente a la prevalencia de anticuerpos presentes en el análisis, el más común fue la DVB (50\%), seguido por neosporosis bovina (36\%), IBR (30\%), Leptospirosis serovar Prajitno (26\%), Leptospirosis

Tabla 2. Prevalencia de anticuerpos contra algunos agentes infecciosos en el ganado bovino, de los resguardos indígenas San Francisco, Toribío y Tacueyó (CAUCA).

\begin{tabular}{|l|c|c|}
\hline Agente & Prevalencia (\%) & Intervalo de confianza 95\% \\
\hline DVB & 50 & $40,75-76,78$ \\
\hline Neosporosis & 36 & $20,54-56,09$ \\
\hline IBR & 30 & $15,41-49,56$ \\
\hline Leptospirosis (Hardjo prajitno) & 26 & $12,97-46,16$ \\
\hline Leptospirosis (Hardjo bovis) & 16 & $6,30-35,45$ \\
\hline Leptospirosis (Pomona) & 10 & $2,62-27,68$ \\
\hline
\end{tabular}

serovar Bovis (16\%) y, por último, Leptospirosis serovar Pomona (10\%); los intervalos de confianza, se presentan en la tabla 2.

Para el análisis de prevalencia de $B$. abortus, agente etiológico de la brucelosis bovina, se preguntó en cada hato si vacunaban a sus terneras contra este. El 53\% de los propietarios afirmaron vacunar a su ganado con la vacuna Cepa 19, pero dudaban sobre las fechas en las que se había realizado la vacunación. En este trabajo, los resultados de laboratorio arrojaron que ningún animal fue positivo $(0 \%)$, lo que es interesante, si se tiene en cuenta que, en otras regiones de Colombia, se han encontrado prevalencias más altas. En el Magdalena y Bolívar (Colombia), en el 2015, hubo una prevalencia de $0,68 \%$ y del $6 \%$, respectivamente, pero se han reportado datos más altos (8\%), en el Caribe Colombiano (Calderón-Rangel et al. 2015). En el 2016, Brasil tuvo una prevalencia de brucelosis de 2,89\% (Diniz et al. 2016) y, para el mismo año, en Ecuador, la prevalencia fue de 2,19\%, considerando un factor de riesgo la no vacunación en el ganado (Zambrano et al. 2016). Según la organización mundial de la salud (OMS), Colombia, junto con Chile, Argentina, México y Perú, son países con incidencia alta en brucelosis (Osorio, 2004; ICA, 2017). En Colombia, esta enfermedad podría estar subestimada (Arenas et al. 2017) y es de las zoonosis menos estudiadas en el país, aunque se realizan actividades de certificación de hatos libres, saneamiento y protocolos de vacunación, pero falta fomentar estudios que se encarguen de construir protocolos de diagnóstico y de vigilancia, que permitan establecer la eficacia de los programas de vacunación en el país.

En la región, se encontró que hay una prevalencia alta de anticuerpos para la DVB (50\%). En otras áreas de Colombia, se han registrado prevalencias más bajas, 32,7\% (Cedeño et al. 2011) y más altas, de 75,7\% (Argaiz, 2016), lo que indica que hay dependencia de otros factores, como la zona del país, que facilitan la persistencia de agentes infecciosos. En Venezuela, se han encontrado prevalencias de 63,2\% (Nava et al. 2013)infectious bovine rhinotracheitis (IBR. Las seroprevalencias para el virus de la DVB han sido altas; sin embargo, aún no existen políticas de control y de erradicación de esta enfermedad. Por otro lado, el 26,67\% de los animales muestreados presentaron co-infección de la DVB y neosporosis bovina y el 23,33\% tuvo co-infección de DVB e IBR (Tabla 3). La seropositividad combinada se pudo presentar, ya que los medios de transmisión son similares, además que las medidas de prevención y de control también influyen en la presencia de estos agentes (Argaiz, 2016). 
Tabla 3. Porcentaje de co-infección entre diferentes enfermedades infecciosas en bovinos, de los resguardos indígenas San Francisco, Toribío y Tacueyó (CAUCA).

\begin{tabular}{|l|r|r|r|r|r|r|}
\hline Enfermedad & Neos & \multicolumn{1}{c|}{ DVB } & \multicolumn{1}{c|}{ IBR } & Leptos (Prajitno) & Leptos (Bovis) & Leptos (Pomona) \\
\hline Neos & $\mathbf{1 , 0 0}$ & 26,67 & 13,33 & 10,00 & 6,67 & 6,67 \\
\hline DVB & 26,67 & $\mathbf{1 , 0 0}$ & 23,33 & 16,67 & 10,00 & 10,00 \\
\hline IBR & 13,33 & 23,33 & $\mathbf{1 , 0 0}$ & 10,00 & 6,67 & 3,33 \\
\hline Leptos (Prajitno) & 10,00 & 16,67 & 10,00 & $\mathbf{1 , 0 0}$ & 16,67 & 6,67 \\
\hline Leptos (Bovis) & 6,67 & 10,00 & 6,67 & 16,67 & $\mathbf{1 , 0 0}$ & 3,33 \\
\hline Lepto (Pomona) & 6,67 & 10,00 & 3,33 & 6,67 & 3,33 & $\mathbf{1 , 0 0}$ \\
\hline
\end{tabular}

Neos $=$ Neosporosis, Leptos $=$ Leptospirosis

En un trabajo reciente, se afirma que la neosporosis bovina debe ser considerada como uno de los causantes más comunes de las enfermedades del sistema reproductivo en el ganado vacuno en América Latina; el estudio arrojó una prevalencia del $64 \%$, en Boyacá (Colombia) (Pulido-Medelín et al. 2016) (Tabla 4), valor mayor al 36\%, obtenido en este trabajo. En Antioquia, se detectó que el $28,3 \%$ de los animales fue seropositivo para neosporosis, hallando anticuerpos en todos los hatos analizados (Bedoya et al. 2018). Es importante destacar que no existe información sobre el impacto real de la enfermedad en Colombia, ya que no se realiza ningún tipo de control oficial (Girata, 2016).

El IBR tuvo una seroprevalencia del 30\%, valor mucho menor al reportado en Montería (Colombia), donde se encontró una prevalencia de 92,5\% (Camacho et al. 2015) (Tabla 4). En un estudio realizado en el 2009, en Chile, la seroprevalencia tampoco fue tan baja (76\%) y los factores de riesgo involucraron las medidas de manejo empleadas en los hatos (Cedeño et al. 2011). En general, se observa que la situación de esta zona del país puede ser mejor que la reportada en otros lugares con tradición productiva (Tabla 4).

La prevalencia para Lesptospira spp., en este trabajo, fue de 17,3\%. En Colombia, se han reportado prevalencias mayores de 23,1 y 41\% (Moreno et al. 2017; Betancur et al. 2013). En países vecinos, como Venezuela, se han reportado prevalencias mayores a las de este trabajo $(80,51 \%)$ (Gontafalla \& Pirela, 2015). Dentro de los factores de riesgo reportados, se encuentra la temperatura, el clima y la humedad, que permiten un medio óptimo para que la bacteria permanezca por varios años (Fávero et al. 2017).

En cuanto a las co-infecciones, el $26,67 \%$ de los animales fueron seropositivos a Neospora caninum y a la DVB, seguidos, con el 23,33\%, para DVB e IBR (Tabla 3). La co-infección menos frecuente fue entre Neospora caninum y Leptospira serovar Pomona y Bovis, con 6,67\%; las demás co-infecciones, se presentan en la tabla 3 . Con respecto a las infecciones triples, un animal fue positivo a los 3 serotipos de Lepstospira sp. (3,33\%), 3 animales (10\%) fueron positivos a Neospora caninum, DVB e IBR y un individuo $(3,33 \%)$ fue seropositivo para todas las enfermedades.

Factores de riesgo. La DVB fue la enfermedad de mayor prevalencia (50\%) y se registró que el área del hato fue un factor de riesgo significativo (Valor $\mathrm{P}=0,046$ ), asumiendo un nivel de significancia de 0,05 . Por otra parte, la seropositividad para IBR también estuvo sujeta a factores de riesgo, como el resguardo indígena (Valor $\mathrm{P}=0,033$ ), el grupo etario (Valor $\mathrm{P}=0,026)$ y el área del hato (Valor $\mathrm{P}=0,010$ ).

Dentro de los factores de riesgo para IBR que se analizaron, se encontraba la zona donde habitaban los animales. Tacueyó, uno de los resguardos indígenas, presentó mayor riesgo, en cuanto a la presencia de estas enfermedades, con respecto a Toribío y San Francisco (Tabla 5); es importante notar que ese resguardo fue el que presentó los hatos con mayor área (Tabla 1). Un factor importante de riesgo para IBR y DVB fue el área del hato. En general, se encontró que los hatos de grandes áreas presentan más riesgo que los pequeños, posiblemente, por la posibilidad de realizar más control y tener mejor manejo en hatos pequeños (Tabla 5). En algunos estudios, se ha reportado que el sistema de producción, en especial los sistemas extensivos, constituyen un factor de riesgo para la presentación de algunas enfermedades, evaluadas en este trabajo. Con respecto a los factores de riesgo para IBR, un factor importante fue el grupo etario, mostrando mayor riesgo en los animales adultos, posiblemente, porque a mayor edad puede haber más posibilidades de exposición a la enfermedad. 


\begin{tabular}{|c|c|c|c|c|c|c|c|c|c|c|c|c|c|c|c|}
\hline 荾 & 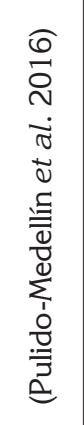 & 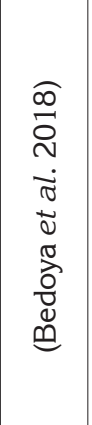 & 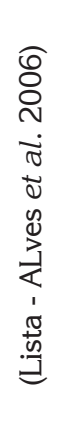 & 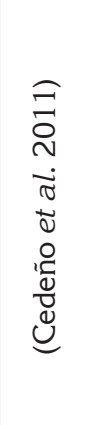 & 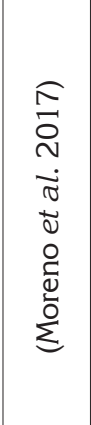 & 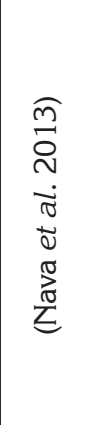 & 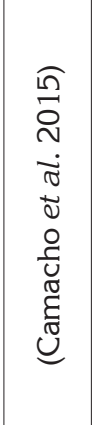 & 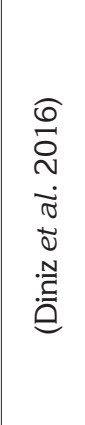 & 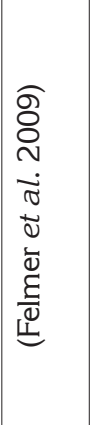 & 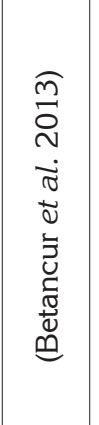 & 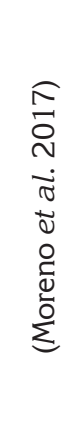 & 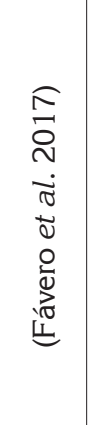 & 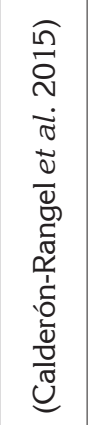 & 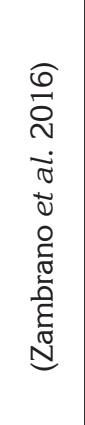 & 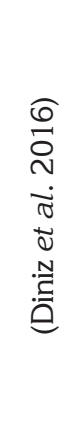 \\
\hline 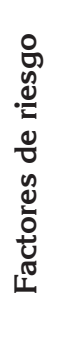 & 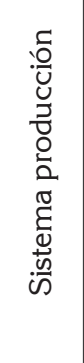 & 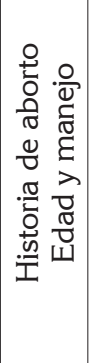 & 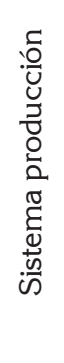 & 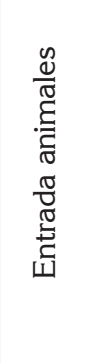 & 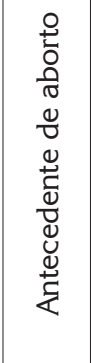 & 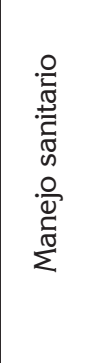 & 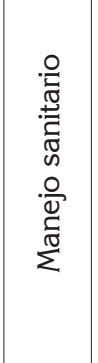 & 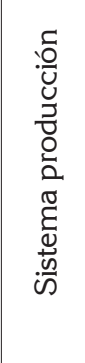 & 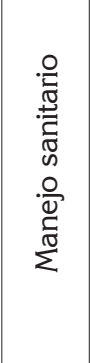 & 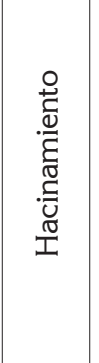 & 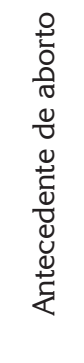 & 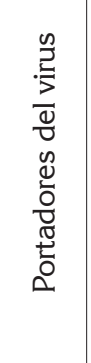 & 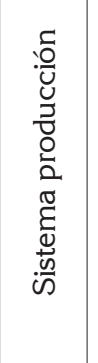 & 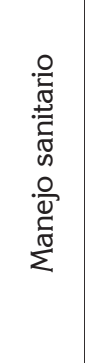 & 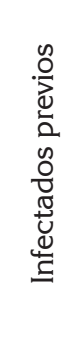 \\
\hline 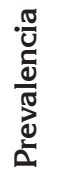 & $\stackrel{\circ}{\text { ఫ̊ }}$ & $\begin{array}{l}\stackrel{\circ}{0} \\
\text { o } \\
\stackrel{\sim}{N}\end{array}$ & $\stackrel{\text { 음 }}{=}$ & $\begin{array}{l}\stackrel{\circ}{\hat{~}} \\
\text { î̀ }\end{array}$ & $\begin{array}{l}\stackrel{\circ}{+} \\
\stackrel{0}{\circ}\end{array}$ & 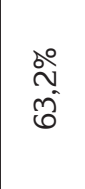 & $\begin{array}{l}\stackrel{\circ}{\circ} \\
\text { ஸे }\end{array}$ & $\begin{array}{l}\text { 今े } \\
\text { o } \\
\text { चे }\end{array}$ & $\stackrel{Ð 0}{\stackrel{0}{2}}$ & $\stackrel{\stackrel{\circ}{\nabla}}{\vec{\gamma}}$ & $\stackrel{\circ 0}{\stackrel{\sim}{N}}$ & $\begin{array}{l}\stackrel{\circ}{\forall} \\
\underset{\forall}{*}\end{array}$ & $\begin{array}{l}\stackrel{0}{0} \\
\text { o } \\
0 \\
0 \\
0\end{array}$ & $\begin{array}{l}\stackrel{\circ}{\circ} \\
\stackrel{\sim}{\sim}\end{array}$ & $\begin{array}{l}\text { ○े } \\
\text { o } \\
\text { ஸे }\end{array}$ \\
\hline 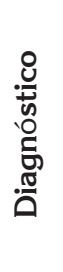 & 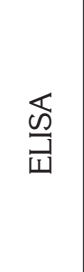 & 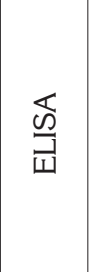 & 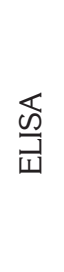 & 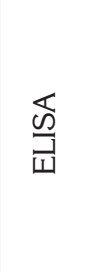 & 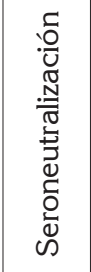 & 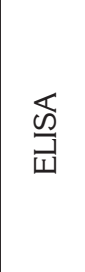 & 吕 & 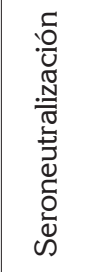 & 蔍 & $\sum^{+}$ & 攴 & $\sum_{\Sigma}^{+}$ & 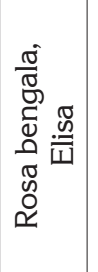 & 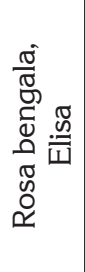 & 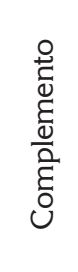 \\
\hline $\mathbf{z}$ & \& & 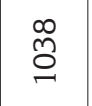 & ஜ্ণে & $\stackrel{\infty}{\sim}$ & ஓे & 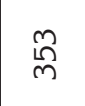 & $\underset{\sim}{ \pm}$ & $\stackrel{\Perp}{\sim}$ & 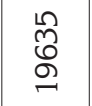 & $\hat{\theta}$ & ஓे & $\underset{\sim}{\stackrel{\sim}{\sim}}$ & $\stackrel{\mathscr{N}}{\sim}$ & $\begin{array}{l}\text { Oి } \\
\text { లె }\end{array}$ & $\stackrel{\stackrel{N}{N}}{\text { N }}$ \\
\hline 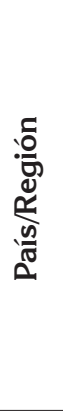 & 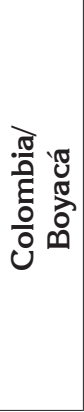 & 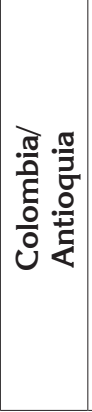 & 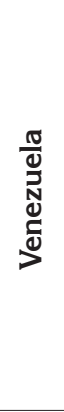 & 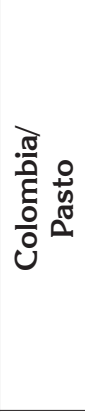 & 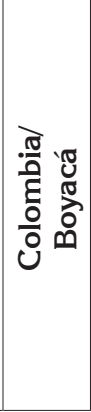 & 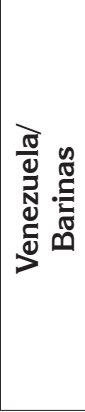 & 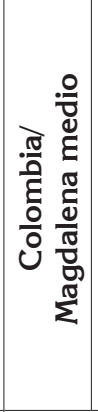 & 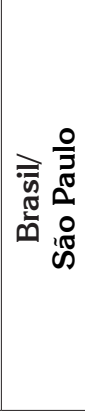 & 产 & 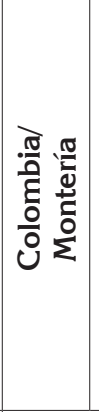 & 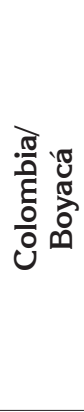 & 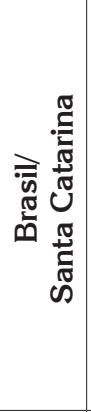 & 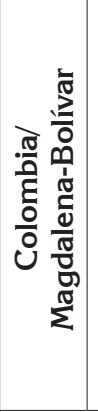 & 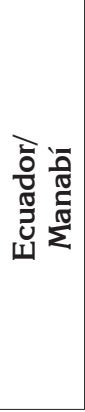 & 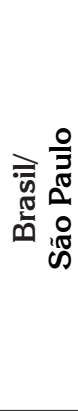 \\
\hline 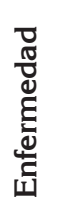 & & 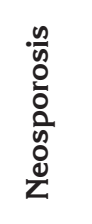 & & & 号 & & & $\stackrel{\underline{\underline{m}}}{\underline{\underline{y}}}$ & & & 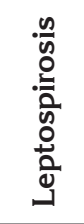 & & & 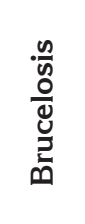 & \\
\hline
\end{tabular}


Tabla 5. Razón de probabilidad para algunos factores asociados a la presentación de DVB e IBR en bovinos, de los resguardos indígenas San Francisco, Toribío y Tacueyó (CAUCA).

\begin{tabular}{|c|c|c|c|}
\hline Enfermedad & Factor & Relación & Odds ratio \\
\hline \multirow{4}{*}{ IBR } & \multirow{2}{*}{ Resguardo } & Tacueyó-San Francisco & 1,98 \\
\cline { 2 - 4 } & \multirow{2}{*}{ Área del hato } & Tacueyó-Toribío & 3,98 \\
\cline { 3 - 4 } & & Grande-Mediano & 1,57 \\
\cline { 2 - 4 } & Grupo Etario & Mediano-Pequeño & 2,68 \\
\hline \multirow{2}{*}{ DVB } & \multirow{2}{*}{ Área del hato } & Jóvenes-Adultos & 2,56 \\
\cline { 2 - 4 } & & Grande-mediano & 1,25 \\
\hline
\end{tabular}

Es importante resaltar que el área del hato se asoció con los resguardos a los que pertenecen, coincidiendo en que los hatos más grandes, en promedio, se encuentran en el resguardo de Tacueyó, lo que podría explicar que los dos sean considerados factores de riesgo para IBR (Tabla 1). La raza fue otro factor de riesgo que se analizó; sin embargo, no hubo diferencia significativa.

En general, el manejo adecuado, el control y la prevención, limitan favorablemente los factores de riesgo, a los que los animales están expuestos diariamente. Otros estudios que han evaluado las causas de estas infecciones, en particular, han estado en común acuerdo en que, la entrada de animales sin pruebas diagnósticas a los hatos, el arrendamiento de toros, el hacinamiento, la presencia de animales seniles y las malas prácticas ganaderas, aumentan el riesgo de adquirir una estas enfermedades (Tabla 5). Es importante notar que, en este trabajo, ninguno de los hatos manifestó estar certificado en BPG, aunque las prevalencias de las enfermedades son similares o menores a las reportadas en otros trabajos (Tabla 4), lo que plantea que la condición de la zona puede ser mejor que la reportada en otros lugares del país, con vocación ganadera. Adicionalmente, la producción ganadera de los resguardos presenta pasturas y razas especializadas, que pueden sugerir una fortaleza productiva para la zona, sobre todo, pensando en el posconflicto, aunque se debe tener especial atención con el tamaño del hato, el grupo etario y los resguardos, debido que fueron factores de riesgo importantes para la zona.

Agradecimientos: A las comunidades indígenas del Cauca, por permitir y apoyar el desarrollo de este trabajo. Conflictos de interés: El manuscrito fue preparado y revisado con la participación de todos los autores, quienes declaramos que no existe conflicto de intereses que ponga en riesgo la validez de los resultados presentados. Financiación: El estudio fue financiado con recursos de la asociación de cabildos de Toribio, Tacueyó y San Francisco, lo cual, consta en el convenio interadministrativo 107 de 2016, celebrado entre la asociación de cabildos, proyecto Nasa y la administración municipal de Toribio.

\section{REFERENCIAS}

1. ACNUR-ONU. 2008. Diagnóstico departamental Cauca. Disponible desde Internet en http://www.acnur. org/fileadmin/scripts/doc.php?file=uploads/media/ COI_2170 (con acceso 17/04/2018).

2. ARENAS, N.E.; ABRIL, D.A.; VALENCIA, P.; KHANDIGE, S.; SOTO, C.Y.; MORENO-MELO, V. 2017. Screening food-borne and zoonotic pathogens associated with livestock practices in the Sumapaz region, Cundinamarca, Colombia. Trop. Anim. Health Prod (Escocia). 49:739-745. https://doi.org/10.1007/s11250-017$1251-6$

3. ARENAS, N.; MORENO, V. 2016. Estudio económico de la infección por Brucella abortus en ganado bovino en la región del Sumapaz, Colombia. Rev. Med. Vet. Zoot. (Colombia). 63(3):218-228. https://doi.org/10.15446/ rfmvz.v63n3.62751

4. ARGAIZ, D.V. 2016. Seroprevalence and risk factors of several bovine viral diseases in dairy farms of San Pedro de los Milagros, Antioquia, Colombia. Rev. CES Med. Vet. y Zootec. (Colombia). 11:15-25. http:// dx.doi.org/10.21615/cesmvz.11.1.2

5. BEDOYA, H.A.; SALES, M.; MARTINS, R.; POLO, G.; CAETANO, A. 2018. Seroprevalence and risk factors for Neospora caninum infection in cattle from the eastern Antioquia, Colombia. Vet. Anim. Sci (USA). https://doi.org/10.1016/j.reuma.2018.03.001 
6. BETANCUR, C.; ORREGO, A.; GONZALEZ, M. 2013. Seroepidemiología de la leptospirosis en bovinos con trastornos reproductivos en el municipio de Montería, Colombia. Rev. Med. Vet. (Colombia). 26:47-55. https://doi.org/10.19052/mv.2633

7. CALDERÓN-RANGEL, A.; ANGULO-MAZA, L.A.; TIQUE, V.P.; RODRÍGUEZ, V.C.; ENSUNCHO, C.F. 2015. Seroprevalencia de brucelosis bovina en dos localidades del Caribe colombiano. Orinoquía. (Colombia). 19(2):203-209.

8. CAMACHO, R.M.; CARVAJAL, L.Y.; CASTELLANOSDOMINGUEZ, Y.Z.; DÍAZ, W.F.; VÁSQUEZ, M.C. 2015. Presença de anticorpos IgG contra infecções reprodutivas de touros reprodutores do Magdalena Médio, Colômbia. Rev. Col. Cienc. Pecu. 28:323-330. http:// dx.doi.org/10.17533/udea.rccp.v28n4a04

9. CEDEÑO, D.; BENAVIDES, B.; HERRERA, C.; CARDENAS, G. 2011. Seroprevalence and risk factors associated to BHV-1 and DVBV in dairy herds in Pasto, Colombia, in 2011. Rev. Lasallista Investig. (Colombia). 8:61-68.

10. DINIZ, J.V.; OCHOA, J.C.; MONTOYA, L.M.; SATRAPA, R.; OKUDA, L.H.; PITUCO, E.M.; MARCELINO, R.R.; OBA, E. 2016. Immune-serological identification of infectious agents with influence on bovine embryo transfer in the north of Brazil. Arch. Med. Vet. (Chile). 48:145-152. http://dx.doi.org/10.4067/S0301732X2016000200003

11. FÁVERO, J.F.; DE ARAÚJO, H.L.; LILENBAUM, W.; MACHADO, G.; TONIN, A.A.; BALDISSERA, M.D.; STEFANI, L.M.; DA SILVA, A.S. 2017. Bovine leptospirosis: Prevalence, associated risk factors for infection and their cause-effect relation. Microb. Pathog. (Inglaterra). 107:149-154. https://doi.org/10.1016/j. micpath.2017.03.032

12. FEDERACIÓN COLOMBIANA DE GANADEROSFEDEGAN, 2011. Situación en Colombia de enfermedades bovinas no sujetas al control oficial: recopilación de resultados diagnósticos 2005-2009. Recopilación de publicaciones y tesis de grado 19982008. Ed. Fedegan (Colombia). 118p.

13. FEDERACIÓN COLOMBIANA DE GANADEROSFEDEGAN, 2015. Estadísticas: inventario gandero, inventario bovino por municipio. Disponible desde Internet en: http://www.fedegan.org.co/estadisticas/ inventario-ganadero (con acceso 17/04/2018).
14. FELMER, R.; ZÚĨIIGA, J.; LÓPEZ, A.; MIRANDA, H. 2009. Prevalencia y distribución espacial de brucelosis, leucosis bovina, diarrea viral bovina y rinotraqueitis infecciosa bovina a partir del análisis ELISA de estanques prediales en lecherías de la IX Región, Chile. Arch. Med. Vet. (Chile). 41:17-26. http://dx.doi. org/10.4067/S0301-732X2009000100003

15. GIRATA, J.G. 2016. Estudio zootécnico de la neoporosis bovina: análisis teórico de orientación para los ganaderos de santander y boyacá. Ed. UNAD (Colombia). 76p. Disponible desde Internet en: http:// repository.unad.edu.co/handle/10596/6861 (con acceso 17/04/2018).

16. GONTAFALLA, G.; PIRELA, R. 2015. Characterization of bovine leptospirosis in Venezuela, Brief review of the disease. Rev. electrónica Vet. (España). 16(2):1-22.

17. HOLMANN, F.; RIVAS, L.; CARULLA, J.; RIVERA, B.; GIRALDO, L.A.; GUZMÁN, S.; MARTÍNEZ, M.; MEDINA, A.; FARROW, A. 2004. Producción de leche y su relación con los mercados: caso colombiano. Ed. Centro Internacional de Agricultura Tropical: CIAT (Colombia). 80p.

18. INSTITUTO COLOMBIANO AGROPECUARIO, ICA. 2017. Colombia: Sanidad Animal 2014. Ed. ICA, Publicación del Instituto Colombiano Agropecuario. Bogotá (Colombia). 163p.

19. LISTA-ALVES, D.; PALOMARES-NAVEDA, R.; GARCIA, F.; OBANDO, C.; ARRIETA, D.; HOET, A.E. 2006. Serological evidence of Neospora caninum in dualpurpose cattle herds in Venezuela. Vet. Parasitol. (Holanda). 136:347-349. https://doi.org/10.1016/j. vetpar.2005.11.027

20. MORENO, G.; BENAVIDES, E.; GUERRERO, B.; CRUZ, A. 2017. Association between seropositivity to BVD virus, Leptospira interrogans and Neospora caninum and abortions in small holder farms in the dairy belt of Boyacá, Colombia. Rev. Investig. Vet. del Perú. 28:1002-1009. http://dx.doi.org/10.15381/rivep. v28i4. 12850

21. NAVA, Z.; BRACAMONTE, M.; HIDALGO, M.; TIBISAY, R.; LADRÓN, E. 2013. Seroprevalencia de la diarrea viral bovina en rebaños lecheros de dos municipios del estado Barinas, Venezuela. Rev. Soc. Venez. Microbiol. 33:162-168. 
22. OSORIO, F. 2004. Brucelosis y estrategias para su control. MVZ-Córdoba (Colombia). 9:466-467. https://doi. org/10.21897/rmvz.494

23. OSTACHUK, A. 2016. Bovine viral diarrhea virus structural protein E2 as a complement regulatory protein. Arch. Virol. (Austria). 161:1769-1782. https://doi. org/10.1007/s00705-016-2835-6

24. PARREÑO, V.; LÓPEZ, M.V.; RODRIGUEZ, D.; VENA, M.M.; IZUEL, M.; FILIPPI, J.; ROMERA, A.; FAVERIN, C.; BELLINZONI, R.; FERNANDEZ, F.; MARANGUNICH, L. 2010. Development and statistical validation of a guinea pig model for vaccine potency testing against Infectious Bovine Rhinothracheitis (IBR) virus. Vaccine. (Holanda). 28:2539-2549. https://doi.org/10.1016/j. vaccine.2010.01.035

25. PULIDO-MEDELLÍN, M.O.; GARCÍA-CORREDOR, D.J.; VARGAS-ABELLA, J.C. 2016. Seroprevalencia de
Neospora caninum en un Hato Lechero de Boyacá, Colombia. Rev. Investig. Vet. del Peru. 27:355-362. http://dx.doi.org/10.15381/rivep.v27i2.11658

26. R CORE TEAM. 2015. R: A Language and Environment for Statistical Computing. R Foundation for Statistical Computing, Vienna, Austria. Disponible desde Internet en: http://www.R-project.org (con acceso 18/04/2018).

27. ZAMBRANO, M.D.; PÉREZ, M.; RODRÍGUEZ, X.; VILLAFUERTE, X.R. 2016. Brucelosis Bovina en la Provincia Manabí, Ecuador. Estudio de los factores de riesgo. Rev. Investig. Vet. del Perú. 27:607. http:// dx.doi.org/10.15381/rivep.v27i3.11995

Recibido: Enero 31 de 2018

Aceptado: Octubre 13 de 2018

Cómo citar:

Rivera, D.C.; Rincón, J.C.; Echeverry, J.C. 2018. Prevalencia de algunas enfermedades infecciosas en bovinos de resguardos indígenas del Cauca, Colombia, 2017. Rev. U.D.C.A. Act. \& Div. Cient. 21(2):507-517. https://doi.org/10.31910/rudca.v21. n2.2018.983 